\title{
Product-Service System Leanness Assessment Model: Study of a UK Manufacturing Company
}

\begin{abstract}
Moustafa Elnadi
Business Administration Department, College of Applied Studies and Community Service, Imam Abdulrahman Bin Faisal University, Dammam, Saudi Arabia
\end{abstract}

\section{Essam Shehab}

School of Engineering and Digital Sciences, Nazarbayev University, Astana, Kazakhstan, and School of Aerospace, Transport and Manufacturing, Cranfield University, Bedford, UK

Purpose - Numerous leanness assessment models were developed for both manufacturing and service sectors. However, little research effort was made to provide an instrument that can be used to measure the leanness level of Product-Service System (PSS). This paper aims to propose an index to assess the leanness of Product-Service System (PSS) in a UK manufacturing company.

Design/methodology/approach - The development of the assessment model was carried out through an iterative process. Commencing from existing literature on lean manufacturing assessment and lean service assessment, the initial model for assessing PSS leanness was developed. This initial model was refined via two consecutive phases. The first one includes semistructured interviews with academic researchers involved in lean projects where their comments were considered. In the second phase, semi-structured interviews with several experts working in different UK manufacturing industries and involved in lean and continuous improvement projects were conducted to reach the final assessment model. After developing the model, the next step was identifying a suitable company for applying the model. The case company was selected because of its commitment to implement lean practices and its ability to participate in this study. After that, data was collected from the case company and the PSS leanness index was calculated using multi-grade fuzzy approach. Finally, areas for further improvement were identified and the results obtained were validated.

Findings - The PSS leanness index computed for the case company indicates that the service offering process provided by the company is generally lean. Areas for further improvement were identified.

Research limitations/implications - This study focused on a single case company and is based on the experts' opinions; this may tend to be biased. However, future study will be performed to multiple-case studies to enhance findings and more empirical research will be conducted to catch more insights into PSS leanness.

Practical implications - This paper provides guidelines to manufacturing companies' managers for measuring PSS leanness index and planning for the future. This index gives information regarding the degree of lean adoption in the service offering process and identifying the gap between the current PSS leanness level and the desired state. 
Originality/value - The proposed model has been developed by the opinion of academicians and industry experts. The proposed model can provide guidelines and directions for managers for PSS leanness assessment.

Keywords: Product-Service System; leanness; assessment; lean

Paper type Research paper

\section{Introduction}

In today's competitive and global market, manufacturing companies are under immense pressure to improve quality, reduce costs, increase productivity, and satisfy the rapidly changing customers' needs and expectations. To meet such challenges and to be competitive, manufacturing companies employ various modern initiatives such as lean manufacturing and Product-service system (PSS). PSS is a business model which aims in providing an integrated products and services package with the sale of use instead of the sale of the product that can fulfil the specific needs of customers (Elnadi and Shehab, 2015; Tukker and Tischner, 2006). PSS can be defined as "The innovation of an organization's capabilities and processes to better create mutual value through a shift from selling product to selling product-service system" (Baines et al., 2007). The implementation of PSS will provide opportunities to both manufacturing companies and customers to realise many advantages. On one hand, manufacturing companies can achieve higher operating efficiency, economic stability, profitability, and improved strategic position. On the other hand, customers will shift the risk of owning the product to the provider of the product and enjoy payment schemes instead of paying the total price of the product at the purchasing stage (Baines et al., 2007; Cook et al., 2006; Maussang et al., 2009; Mont, 2002; Tukker and Tischner, 2006).

There are three types of PSS, starting from the traditional way of selling the product with some additional services provided to customers (Product-oriented). Motiving to the second type namely (Use-oriented) that focuses on the sale of use or the availability of the product via activities like leasing or sharing. Finally, the last type is (Result-oriented) focusing on selling the functionality or end results instead of the product (Baines et al., 2007; Elnadi and Shehab, 2016; Sakao et al., 2009; Tukker, 2004; Tukker and Tischner, 2006; Yang et al., 2009).

Along with PSS, lean thinking has grown significantly over time, and has been applied not only in manufacturing companies but also in other service sectors such as universities, banks, healthcare, insurance, and government, achieving also outstanding results (Delgado et al., 2010; Martinez, 2019; Narayanamurthy and Gurumurthy, 2016a; Piercy and Rich, 2009; Radnor and Bucci, 2011; 
Swank, 2003; Yadav et al., 2019). Derived from the Toyota Production System (TPS), lean practices improve flow via differentiating value-added activities from non-value-added activities and eliminating waste (Burch and Smith, 2019; Pagliosa et al., 2019; Saxby et al., 2020). Thus, lean management is considered by many academics and practitioners as a philosophy that if successfully implemented, can result in manufacturing excellence and competitiveness (Al-Najem et al., 2013; Amin et al., 2020).

However, many studies reveal that companies fail to achieve the desired outcomes from implementing lean because of the absence of an appropriate method that can evaluate and monitor the degree of lean implementation (Bidhendi et al., 2019). According to, Narayanamurthy and Gurumurthy, (2016b), lean principles are successfully applied by many manufacturing companies, but the approach that can be used to assess the leanness level has not been.

Leanness assessment is the procedure used to measure the extent to which an organisation is adhere to the implementation of lean principles and practices by identifying the current level of leanness achieved (Almutairi et al., 2019; Narayanamurthy and Gurumurthy, 2016b; Saleeshya and Binu, 2019). Therefore, it is necessary for companies that implement lean to regularly track their leanness level to figure out their lean implementation status and to determine any future improvements (Yadav et al., 2019). According to Amin et al., (2020) and Narayanamurthy and Gurumurthy, (2016a), a proper leanness assessment should possess some features such as: measurable, relative, fuzzy logical, allow to track and assess performance, comprehensive, realistic, integrative, objective, assist in determining the current status and identify any future improvement opportunities.

In the last decade, various leanness assessment models and techniques were developed either on manufacturing or non-manufacturing sectors. However, little work has been done in the area PSS leanness assessment. Therefore, the aim of this study is to fill this research gap by developing an index that can measure PSS leanness and address the previous mentioned characteristics.

This article has the following structure. Literature review on leanness assessment and multi-grade fuzzy approach is discussed in Section 2. Section 3 presents the research methodology used in this study. Section 4 provides an explanation of the model. Computing the PSS leanness index and identifying improvements areas for the case company will be presented in sections 5 and 6 . The results are validated in Section 7. Finally, the conclusion of this study is presented in section 8. 


\section{Literature review}

\subsection{Leanness assessment}

Despite the evidence that suggest lean manufacturing as an effective approach used by companies to achieve operational excellence, many cases have been reported in the literature showing that such benefits have not been realised. According to Arya and Choudhary (2015); Bhasin (2012); Bidhendi et al., (2019), and Narayanamurthy and Gurumurthy (2016b) lean benefits cannot be realised, and lean practices cannot be sustained due to the absence of a comprehensive measure used to evaluate lean performance. Consequently, the need for a standard method used to evaluate and assess the performance of lean practices become crucial (Bayou and Korvin, 2008).

Performance assessment become one of the important issues for manufacturing and non-manufacturing companies, to have control over their processes. Many models and techniques have been developed by researchers to evaluate the performance of lean and the term leanness have been used as a metric to assess the current level of lean implementation and identify areas of further improvement to realise the required progress (Alemi and Akram, 2013; Stone, 2012; Urban, 2015). By identifying the leanness level, companies can improve productivity, reduce costs, lead time, defects, and makes profitability more viable (Anvari $e t$ al., 2013). Through the literature reviewed many studies have examined leanness either on manufacturing or no-manufacturing sectors. According to Liu et al., (2017) three main types of lean assessment exist. The first type focuses on lean practices as a lean assessment metrics such as: TPM, JIT, VSM, and 5S. In the second type, the effect of lean implementation on the performance was examined focusing on factors such as: time and cost. The third type contains a mix of the previous two types as well as using lean enablers, attributes, and criteria to develop a holistic assessment approach.

Based on five lean dimensions (quality, customer, process, human resources, and delivery suppliers), Dahda et al., (2020) proposed a Fuzzy Leanness Index that measure the case company's level of lean practices implementation. By applying a mix of DEMATEL and fuzzy-VIKOR multi-criteria decision-making approach, Kumar Singh and Modgil (2020) identified the lean practices performance of automotive industry supply chain in India. Additionally, they have determined eight lean supply chain practices and ranked them according to their significant impact on the supply chain leanness. Likewise, Saleeshya and Binu, (2019) combined neural network and fuzzy logic to develop a neuro-fuzzy leanness assessment model that evaluate manufacturing system leanness according to 10 leanness aspects (inventory, scheduling, flexibility, ergonomics, product, process, management, workforce, supplier relationship, customer relationship). Based on five lean perspective namely financial, customer, processes, employees, and suppliers, 16 lean objectives, and 51 lean criteria, Seyedhosseini and Ebrahimi-Taleghani (2015) developed a leanness assessment model that merge balanced score card (BSC) with group fuzzy analytic network (GFANP) to assess the leanness level of auto part manufacturing companies. 
Garza-Reyes et al., (2018) developed a model that assess the readiness level of lean manufacturing using data collected from 37 pharmaceutical organisations in Europe. The model is based on six main pillars of lean manufacturing, these pillars were: processes, planning and control, human resources, top management and leadership, customer relations, and suppliers' relations. Based on 38 lean practices, dos Santos Bento and Tontini (2019) developed an instrument using 5 points Likert's scale to measure the lean manufacturing maturity of 90 manufacturing companies in Brazil. Also, Pakdil and Leonard (2014) used both quantitative and qualitative dimensions to develop a leanness assessment tool (LAT). The quantitative dimensions include time effectiveness, quality process, cost, human resources, delivery, customer, and inventory. On the other hand, the qualitative dimensions contain quality, process, customer, human resources, and delivery. This LAT was helpful for companies to identify improvement needs in lean implementation. Karlsson and Åhlström (1996) developed a checklist of nine lean practices to assess the leanness level. Soriano-Meier and Forrester (2002) used the same nine variables applied by Karlsson and Ahlström to assess the leanness of 30 UK ceramic tableware manufactures. Narayanamurthy and Gurumurthy (2016) evaluated the continuous improvement of lean implementation using s systematic leanness index. This index was developed based on the application of the Graph-Theoretic Approach (GTA) that can measure the degree of lean implementation according to five main lean elements (supplier interface practices, management practices, human resource practices, process practices, and customer interface) and 22 lean sub-elements.

Sangwa and Sangwan (2018) presented a conceptual framework based on key performance indicators (KPIs) to measure lean performance. Seven key areas were evaluated in the framework namely: manufacturing process, new product development, human resource management, finance, administration, customer management, and supplier management. Under these seven categories there were 26 dimension and 119 key performance indicators. By assessing the performance enterprise leadership process, life-cycle processes and enabling infrastructure processes, the Lean Enterprise Self-Assessment Tool (LESAT) was developed by Nightingale and Mize (2002) to assess lean implementation in the aerospace industry. Based on the rapid plant assessment tool (RPA) introduced by Goodson (2002), Makui et al., (2014) presented the Total Rapid Assessment (TRA) tool based on 15 assessment categories to evaluate the degree of lean implementation.

Vidyadhar et al., (2016) computed the leanness index for SMEs in India, they developed a model using fuzzy logic approach. They found that the case company was very lean. In the same way, Matawale et al., (2015) developed an index to measure the degree of manufacturing company supply chain leanness level using trapezoidal fuzzy numbers set. This index was helpful for the Indian case company to identify areas for further improvement in its lean journey implementation. Also, Al-Najem et al., (2013) measured the leanness readiness level of 50 small and medium-sized manufacturing companies in Kuwaiti by conducting 
statistical analysis of data collected from semi-structured interviews with 27 senior managers. The proposed framework evaluates lean readiness level according to six lean quality practices (processes, planning and control, human resources, top management and leadership, customer relations, and supplier relations).

Additionally, Bayou and Korvin (2008) used Honda Motor Company as a benchmarking to measure the leanness level of General Motors and Ford Motor Company. The system of Ford founded to be $17 \%$ leaner than General Motors's system. Gupta et al., (2013) evaluated the performance of lean practices of a manufacturing company in India using Excel-based template, as well as, they have identified the main enablers and critical success factors for lean implementation using interpretive structural model (ISM). They found that organisational culture and human resources management are considered the most two important enablers in implementing lean strategy. Bhasin (2011) assessed the leanness level of 20 UK manufacturing companies using a model of 104 indices.

Moreover, Susilawati et al., (2015) developed an assessment method to measure the degree of lean implementation by using data collected from Indonesia. The assessment is based on using fuzzy logic, as well as value stream mapping. Using multi-grade fuzzy logic, Vinodh and Chintha (2011) computed the leanness index of an Indian electronic manufacturer. The total leanness index computed based on the indices calculated for five lean enablers, 20 lean criteria and many lean attributes. Likewise, Vimal and Vinodh (2013) combined artificial network and fuzzy logic to compute the leanness level using the same model provided by Vinodh and Chintha (2011). Additionally, Bidhendi, et al., (2019) used fuzzy-based analytic network process to develop a weighted leanness assessment model that can score organisations' leanness performance based on the interdependent relationships between performance metrics. Amin et al., (2020) developed leanness assessment model using triangular linguistic fuzzy membership function. They evaluated the lean implementation performance of the case company before applying lean tools and after applying lean tools. Fuzzy logic was also used by Anvari et al., (2013) to calculate manufacturing systems' lean score in relation to lead time, cost, defects, and value. Moreover, Kumar et al., (2013) implemented fuzzy TOPSIS methodology to calculated and compared the leanness status of three manufacturing firms via multi-criteria decision-making model that consists of five lean enablers (supplier issues, investment priorities, lean practices, organisational issues, and customer issues).

From the socio-technical perspective Wong et al., (2014) used analytic network process (ANP) to develop an index to measure the leanness level of organisations. The assessment model is based on three performance determinants and four performance dimensions. The performance determinants include cost, quality, and on time delivery, while the performance dimensions include corporate and intra-organization alignment, projects and IT implementation, planning control and execution, and finally resource capability. By using data envelopment analysis (DEA), Azadeh et al., (2015) evaluated the leanness level of packing 
and printing organizations in Iran, additionally they have used the sensitivity analysis to identify the effect of each leanness factor on lean strategy.

In non-manufacturing sector, Tortorella et al., (2019) proposed a method to evaluate the implementation of lean practices in hotels' supply chain using semi-structured interviews with six high quality hotels. The assessment was based on ten main lean practices. By using benchmarking, Martinez (2019) compared the current leanness level of a home services provider (electricians, plumbers, painters, housework, gardening) with automotive industry suppliers. He proposed an assessment tool (Lean Index - LI) to conduct the comparison between the two sectors.

Also, Narayanamurthy et al., (2018) provided a framework to assess lean implementation readiness in healthcare by using stakeholder theory and fuzzy logic. The framework provides healthcare institutions with improvement areas. The main elements used in the assessment were leadership and executive team, frontline management team, lean sensei and team, patients and other customer groups, suppliers' groups and finally, healthcare institution attributes. By using multi-grade fuzzy logic, Almutairi et al., (2019) assessed the implementation of lean principles in healthcare sector's supply chain. The leanness assessment model constructed upon five main lean enablers (medical management responsibility, hospital supply chain processes management, medical human resources, consumer relationship, and supplier relationship), ten lean criteria, and 38 lean attributes.

Furthermore, the Healthcare Lean Assessment (HLA) framework developed by Guimarães and de Carvalho (2014) used to assess the current state of lean implementation and identify areas of further improvements. Karvonen et al., (2012) imitated the Lean Enterprise Self-Assessment Tool (LESAT) to assess the leanness level of software development companies.

Malmbrandt and Åhlström (2013) evaluated lean enablers, lean practices and operational performance to determine the degree of lean service implementation using an instrument of 34 items. Furthermore, Cuatrecasas (2004) and Apte and Goh (2004) evaluated the performance of lean implementation in a hotel checkout service and insurance claim handling, respectively.

The literature review shows the following drawbacks of previous research efforts:

- The majority of the previous studies focused mainly on manufacturing organisations with few numbers of studies concentrated on the service sector. This indicates that the lean implementation maturity is higher in manufacturing sector than the service sector.

- In most of the previous studies data was collected and leanness level was measured for a single case study. Narayanamurthy and Gurumurthy (2016b) stated that the large percentage of a single case study can be related to "the emerging nature of the topic and researchers attempt to initially perform case-based study to identify the constructs and attributes that are to be validated". 
- Large number of the previous studies apply fuzzy technique to avoid the limitations of conventional crisp methods. Sreedharan et al., (2019) define Fuzzy logic as "a multi-value logic that lets transitional values to be stated between common ones like low/high, true/false, good/bad, etc". Many researchers advocate the application of fuzzy approach to overcome any bias, impreciseness, and ambiguity associated with experts' judgements and opinions (Almutairi et al., 2019; Amin et al., 2020; Bidhendi et al., 2019; Sridharan and Suresh, 2017). Fuzzy logic approach is the most commonly used technique in lean assessment because leanness and lean evaluation cannot be estimated with high level of certainty, where describing and explaining the leanness level of each enabler or criterion can vary from one expert to another with different grades such as extremely lean, lean, or leaner (Bidhendi et al., 2019).

\subsection{Multi-grade fuzzy logic}

In recent years multi-grade fuzzy approach has been widely used in various fields in the literature particularly in operations management field (Almutairi et al., 2019; Mishra and Mishra, 2018). For example, Kalyan et al., (2019) developed an index to measure industrial symbiosis of a tire-manufacturing organisation using multi-grade fuzzy approach. Mishra and Mishra, (2018), computed marketing-based flexibility index by using multi-grade fuzzy approach. Additionally, the same approach was applied by Vinodh and Chintha (2011) and Elnadi and Shehab (2016) to develop an index that measure the leanness level. Furthermore, sustainability was evaluated by implementing the same approach (Nallusamy et al., 2016; Vimal et al., 2015). By following the same technique Vinodh et al., (2010) evaluated the agility level of a manufacturing company. In the service sector, Almutairi et al., (2019) applied multi-grade fuzzy approach to assess supply chain leanness level in the healthcare sector and Suresh and Patri (2017) used the same approach to evaluate health-care dispensary agility.

The implementation of multi-grade fuzzy logic requires the development of hierarchical levels of enablers, criteria, and attributes (Vimal et al., 2015). Then, determining the weights of each level followed by ranking process (Almutairi et al., 2019). This approach involves assessment based on five-point fuzzy grade, where $\mathrm{I}=\{10,8,6,4,2\}$ (Almutairi et al., 2019; Mishra and Mishra, 2018; Vimal et al., 2015; Vinodh and Chintha, 2011). The index values can be labelled with scales such as: 'extremely lean', 'lean', 'generally lean', 'not lean', 'extremely not lean' (Vinodh and Chintha, 2011). Other authors used a label of 'extremely flexible', 'flexible', 'generally flexible', 'not flexible', 'extremely rigid' (Mishra and Mishra, 2018). Also, Vimal et al., (2015) used grades of 'extremely sustainable', 'sustainable', 'generally sustainable', 'not sustainable', and extremely not sustainable'.

Multi-grade fuzzy approach was confirmed by many researchers as mentioned before to be effective to develop indices used in performance assessment for many reasons: 
- It is more objective than other approach and it can overcome any fluctuation in variables values, as it can deal with the vagueness and imprecision associated with experts' judgement in the assessment process.

- It is very simple to be implemented and understood with few rules and calculations.

- It provides more realistic values thanks to the application of linguistic assessment.

- It is a user-friendly technique from the industrial practitioners' perspective.

Thus, in this study the multi-grade fuzzy approach was applied for computing the leanness level of PSS due to the relative advantages associated with this approach over other techniques. The literature review indicated that little research effort was made to provide a method or instrument that can be used to measure the leanness level of PSS. To overcome this shortcoming, an assessment model was developed in this project to evaluate PSS leanness level, as well as, validating the model via real life case study.

\section{Research methodology}

The research methodology contains three basic phases as presented in Figure 1. Phase (1) Model development

The model development phase started with conducting extensive literature review on lean assessment, evaluation, and measurement in both manufacturing and non-manufacturing sectors. This literature review resulted in developing the initial conceptual assessment model. Then, the initial model was presented to academic researchers associated with lean projects via semistructured interviews that held individually and took from 45 to 60 minutes. The aim of these interviews was to refine the initial model through researchers' validation and testing the model feasibility.

Next, it was critical to validate the model from the industrial practitioners' perspective. Thus, five semi-structured interviews were conducted independently with industry experts working in different UK manufacturing industries such as: document management, aerospace, transportation, trucks and buses. Each interview ranged from 50 to 60 minutes. The five experts were selected based on some criteria such as their involvement and participation in lean and continuous improvement projects and their working experience (ranged from 15 to 30 years) as presented in Table 1. The purpose of these interviews was to gather any new information related to the proposed model and to confirm already known information. By discussing the model - its structure and its capability to evaluate the level of PSS leanness - with the five experts and responding to their valuable comments, the model second version was modified resulting in the third and final version. 


\section{Phase (2) Data collection}

The second phase of the research methodology started with the identification of a suitable company that can be used as a case study. A case study approach was chosen because of its distinct advantage in situations when in-depth detailed questions are asked about a contemporary set of events over which the investigation has little or no control (Yin, 2017). The selection of the case company has been identified based on some criteria, including the willingness to participate, the employment of PSS, and the enthusiasm to apply lean practices in the service offering process. All the information about the case company is presented in section 5.1 .

As mentioned before in section 2.2, most of the previous studies used a single case study to collect data and measure the leanness level because of the emerging nature of the topic and to determine the attributes that are to be measured (Narayanamurthy and Gurumurthy, 2016b).

After that, data was collected from ten experts working in the same case company whose details are given in Table 1 and the PSS leanness level was measured using multi-grade fuzzy approach. Ten experts are a reasonable number to be used to collect the required data and calculate PSS leanness index. Many researchers used only five experts to collect data and calculate the leanness level of the case company (Almutairi et al., 2019; Elnadi and Shehab, 2016; Vinodh and Balaji, 2011; Vinodh and Chintha, 2011).

Table 1. List of experts job roles and years of experience

\begin{tabular}{|c|l|c|}
\hline Expert No. & \multicolumn{1}{|c|}{ Role } & Years of experience \\
\hline E1 & CEO & 40 \\
\hline E2 & CI Manager & 27 \\
\hline E3 & Head of Services & 30 \\
\hline E4 & Operating Manager & 26 \\
\hline E5 & CRM Manager & 24 \\
\hline E6 & Head of Aftersales and Business development & 40 \\
\hline E7 & CFO & 33 \\
\hline E8 & HR Director & 25 \\
\hline E9 & Sales Director & 36 \\
\hline E10 & Business Improvement Manager & 23 \\
\hline
\end{tabular}

Phase (3) Identifying areas for further improvements and validation

Finally, in the last phase after measuring PSS leanness level for the case company, areas that need further improvement were identified as presented in section 6 and the results obtained were validated via quantitative and qualitative validation methods as presented in section 7. 


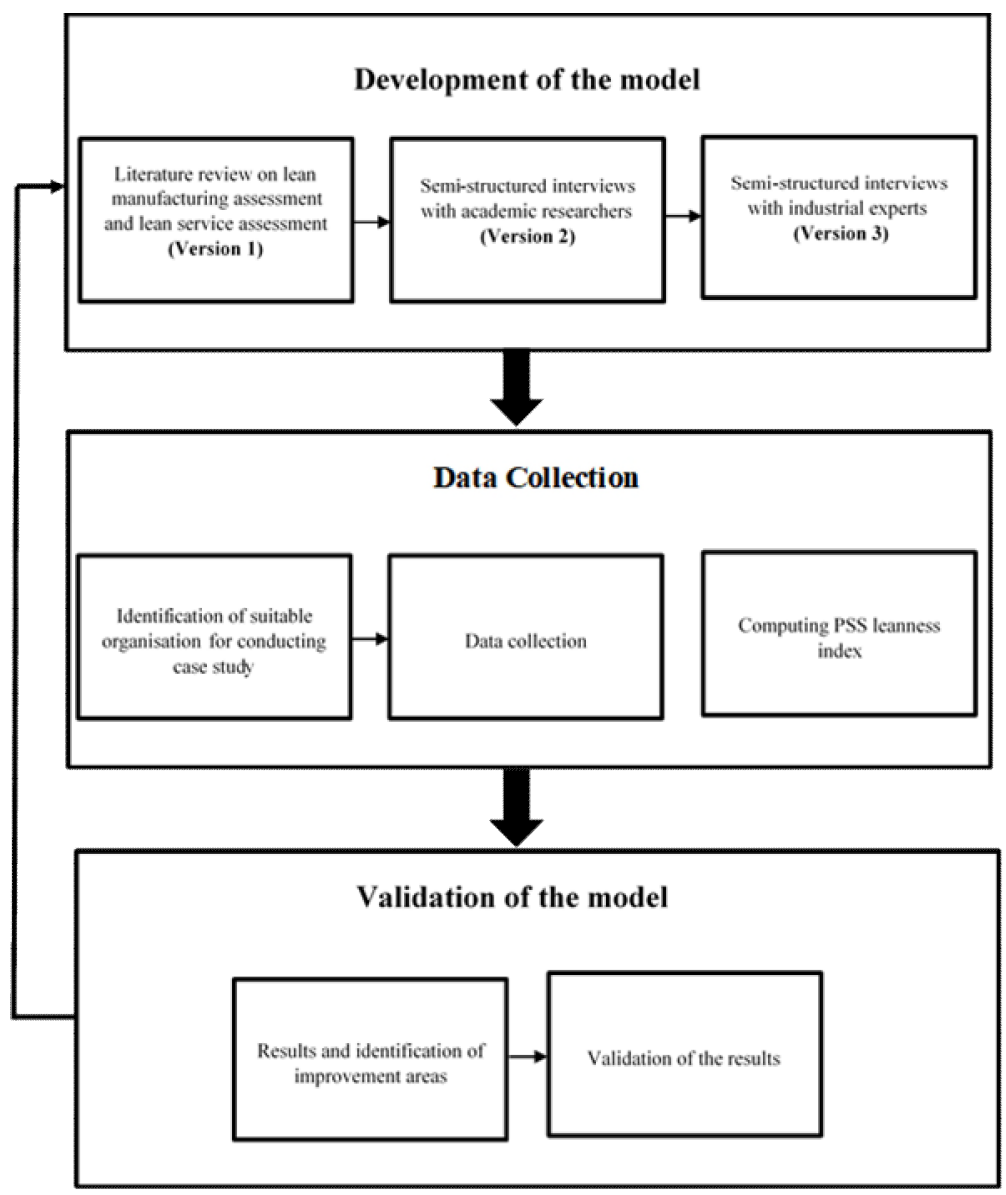

Figure 1. Research methodology

\section{Product-Service System leanness assessment model}

The PSS assessment model comprises three main levels namely: enablers, criteria, and attributes as illustrated in Figure 2. In the first level there are five main enablers, 21 criteria in the second level and finally 73 attributes in the third level. Each level will be used in assessing the former level.

For example, the PSS leanness index will be calculated based on the sum of the indices calculated for the five enablers. Using the same procedures, the index of each enabler will be calculated based on the indices calculated for each criterion pertaining to each enabler. Finally, the evaluation of the criteria will depend on the assessment scores of the attributes. All the enablers, criteria and attributes used are presented in Appendix 1. 


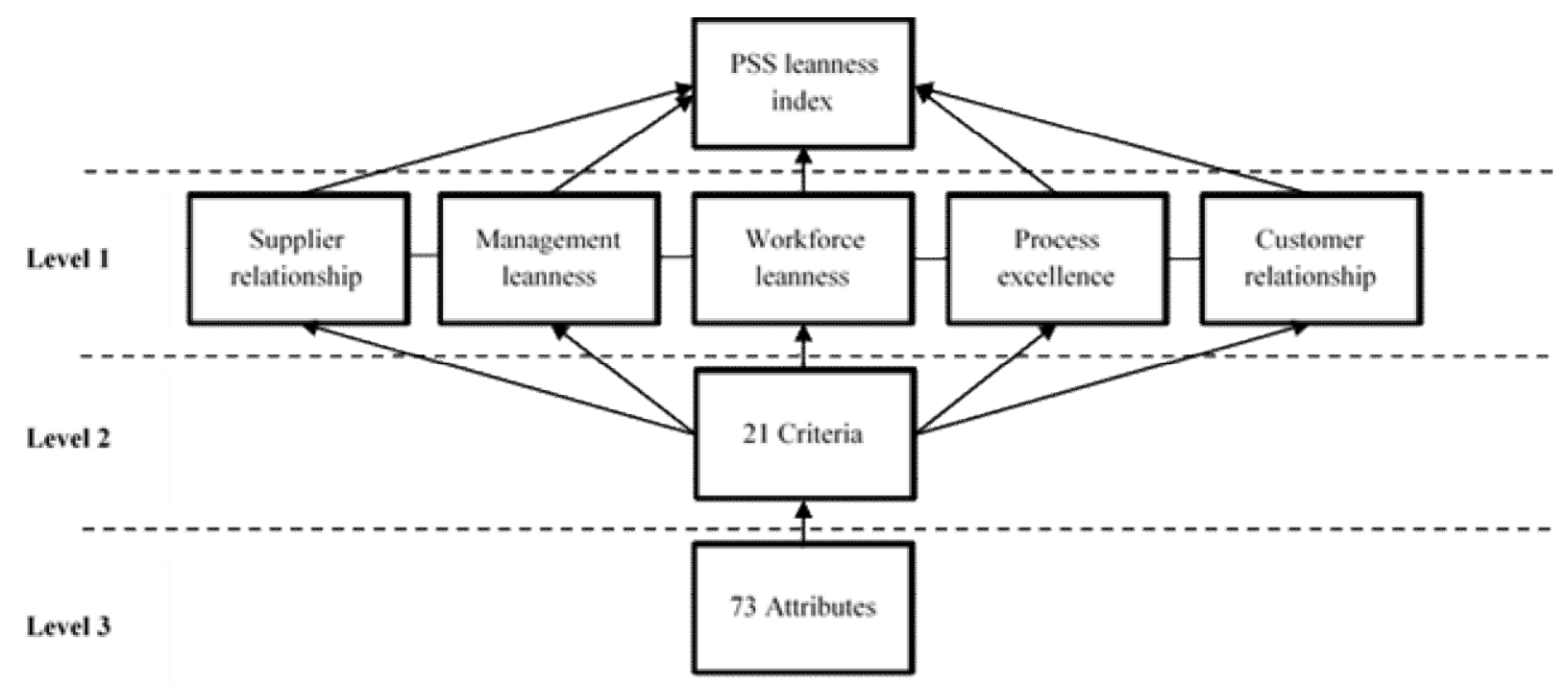

Figure 2. Assessment model

\subsection{Supplier relationship}

As the main objective of lean implementation is to meet customers' demands through responding quickly to their changing needs and providing goods and services at the highest quality, the role of suppliers and the material procurement system become crucial in the successful implementation of lean (MacDuffie and Helper, 1997).

In this manner, manufacturing companies find that it is more productive to deal with suppliers aware of the lean tools and techniques and apply these tools in their processes. For the successful implementation of lean principles, manufacturing companies should involve key suppliers the in the manufacturing process, build long term relations and commitment with them and improve communication with them. Similarly, suppliers should deliver the required materials in the right quantity, quality and point of use every time (Handfield, 1993).

\subsection{Management leanness}

According to Elnadi and Shehab (2016) management leanness is considered one of the main pillars for the successful lean implementation. Three basic factors related to management leanness, namely: culture of management, leadership, and management commitment.

Bhasin (2011) mentioned that $80 \%$ of becoming lean is culture related, additionally one of the mean reasons for lean failure related to culture and management issues (Bhasin, 2011; Mann, 2017). For companies to succeed in its lean journey, the management should have the culture of continuous improvement, problem solving and waste elimination (Loyd et al., 2020). Moreover, management should feel enthusiastic about lean philosophy and understand that it is not just the implementation of tools and techniques. 
Besides the important role of management culture, the role of leadership is vital in the lean implementation process. Womack and Jones (1996) mentioned that there should be three basic types of leaders for a company to transform to lean. These types are the specialist, the champion, and finally the committed. The leader will communicate the importance and expected benefits of lean implementation, create the motivation among employees, create the required environment, and empower employees to make decisions (Sisson, 2019). Finally, all managers at all levels of the company should belief that lean is the right way for the company to improve its capabilities. Senior management should demonstrate full commitment to lean philosophy and provide all the required resources, budget, and investment (Loyd et al., 2020).

\subsection{Workforce leanness}

Harris and Harris (2007) presented that a lean workforce is a workforce with the right number of workers, with the right skills and workforce that work safely and proactively without errors. Successful lean implementation requires a workforce that accept lean initiatives, motivated, trained, committed, rotated between jobs and engaged in the improvement process (Almutairi et al., 2019; Elnadi and Shehab, 2015, 2016).

\subsection{Process Excellence}

Process excellence is the systematic management of all the tasks and activities required for producing a product or a service to achieve world class performance (Lee and Dale, 1998; Trkman, 2010).

Lean is mainly about adding value this can be realised by the efficient use of resources, eliminating nonvalue-added activities and wastes, the efficient utilization of tools, creating process flow, and pulling products and services rather than pushing them on the marketplace (Womack and Jones, 1996).

\subsection{Customer relationship}

One of the main requirements for the successful application of any lean initiatives is customer relationship (Antony and Desai, 2009; Elnadi and Shehab, 2015, 2016; Suárez-Barraza and Ramis-Pujol, 2010). The start point of any lean initiatives is identifying customer value (Womack and Jones, 1996). Customers see value as obtaining the precise product or service required, in the right quantity, at the right time, with perfect quality, and at the right price (Bicheno, 2008). Since value is determined by the customers, it is essential to develop a good relationship with them. Thus, managers should work hard to identify customers value to increase the accuracy of all the forecast plans and the level of products and services quality.

\section{Case study}

\subsection{The case company}

The case study has been carried out in a UK manufacturing company. The company is specialised in large automotive manufacturing and it is considered one of the leading international providers of efficient 
commercial vehicles with European market share of $14.5 \%$ in 2018. The name of the company will not be revealed due to confidentiality agreements and will be referred to as ABC company.

ABC company provides its customers with two major models of PSS. The first one is Operating Lease Agreement and the second one is Contract Hire. Additionally, the company launched a project to implement lean practices in the service offering process only few years ago with the aim of enhancing the current process to: increase efficiency and internal and external customer satisfaction, reduce work in progress, and invoices in query. Consequently, the proposed model in this study was useful for the company, to identify the current situation of its lean performance and to determine areas for further improvements. The company was keen to collaborate and to provide all the required data to develop the model and measure the PSS leanness level.

\subsection{Assessment of $A B C$ PSS leanness}

In this section the PSS leanness index for ABC Company will be calculated, as well as all the steps applied in the evaluation process will be presented. Ten experts participated in the assessment process.

Based on Vinodh and Chintha (2011) and Vimal et al., (2015) steps in using multi-grade fuzzy approach, ABC Company's PSS leanness index presented by $(I)$ will equal to the product of the overall assessment factor $(R)$ and the overall weight ( $W$ ) as presented in Equation (1).

$$
\mathrm{I}=\mathrm{W} \times \mathrm{R}
$$

ABC Company's PSS leanness index will range from 0 to 10 as follow:

\section{(Less than 2)}

\section{Extremely not lean}

\section{$(2-4)$}

Not lean
(4-6)

Generally lean
(6-8)

(8-10) 
- Step (2) Identifying each criterion index

- Step (3) Calculating each enabler index

- Step (4) Computing the total PSS leanness index for the case company

Step (1) Determining each enabler, criterion, and attribute weight (relative importance)

Because of the small sample size and to avoid the influence of the outliers and extreme values related to using mean, median was used to calculate the weight (relative importance) and the experts should follow the condition presented in Equation (2). In Table 2 all the weights (relative importance) for each enabler, criterion and attributes are summarized. Additionally, all the experts' evaluation scores of each attribute are presented.

$$
\sum_{i=1}^{i} w i=1
$$

Step (2) Identifying each criterion index

Using Equation (3), the single factor for each criterion will be calculated.

$$
\begin{aligned}
& I_{i j}=\left[\begin{array}{ccc}
R_{11} & \cdots & R_{1 n} \\
\vdots & \ddots & \vdots \\
R_{k 1} & \cdots & R_{k n}
\end{array}\right] \times\left[\begin{array}{c}
W_{1} \\
\vdots \\
W_{k}
\end{array}\right] \\
& =\left[\left(\sum_{k=1}^{k} R_{k 1} \times W_{k}\right) \cdots\left(\sum_{k=1}^{k} R_{k n} \times W_{k}\right)\right]
\end{aligned}
$$

For example, the calculation related to supplier quality criterion is shown as follows:

Weights pertaining to the supplier quality criterion $\mathrm{W}_{11}=(0.1,0.2,0.2,0.4)$

Assessment scores pertaining to the supplier quality criterion is given by

$$
\mathrm{R}_{11}=\left[\begin{array}{cccccccccc}
8 & 3 & 6 & 6 & 5 & 4 & 6 & 6 & 4 & 8 \\
4 & 4 & 5 & 7 & 4 & 4 & 5 & 4 & 3 & 3 \\
7 & 7 & 5 & 8 & 7 & 7 & 0 & 5 & 4 & 10 \\
5 & 5 & 5 & 8 & 7 & 7 & 9 & 8 & 4 & 3
\end{array}\right]
$$

Index pertaining to the supplier quality criterion is given by 


$$
\begin{gathered}
\mathrm{I}_{11}=\mathrm{W}_{11} \times \mathrm{R}_{11} \\
\mathrm{I}_{11}=(5,4.5,4.6,6.8,5.5,5.4,5.2,5.6,3.4,4.6)
\end{gathered}
$$

Using the same procedures, all the indices pertaining to the remaining lean criteria were calculated as presented in Table 3.

Table 2. Weights and assessment scores for ABC Company (Refer to Appendix 1. For Enablers, Criteria, and Attributes)

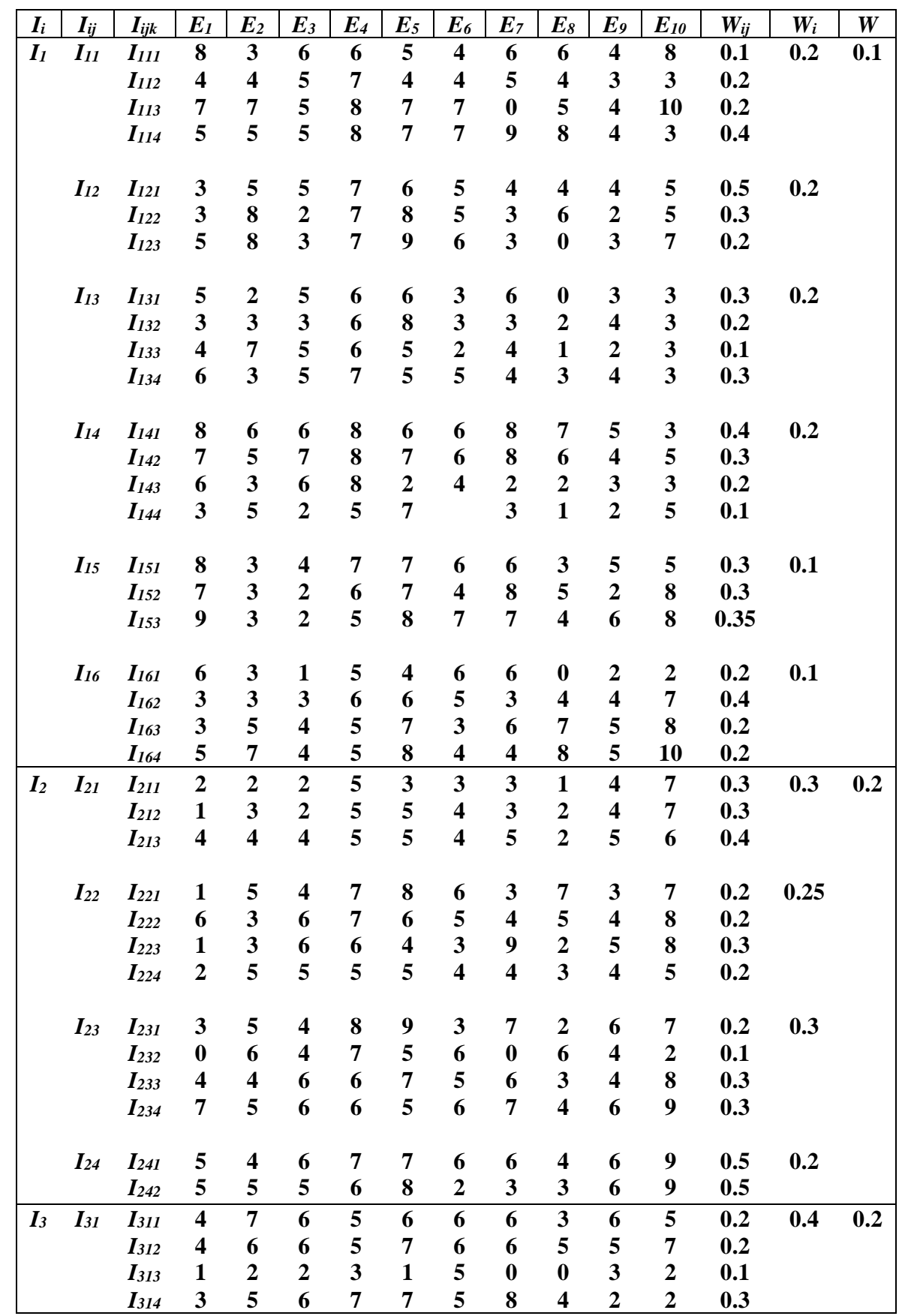




\begin{tabular}{|c|c|c|c|c|c|c|c|c|c|c|c|c|c|c|c|}
\hline $\boldsymbol{I}_{i}$ & $I_{i j}$ & $I_{i j k}$ & $E_{1}$ & $\boldsymbol{E}_{2}$ & $E_{3}$ & $E_{4}$ & $\boldsymbol{E}_{5}$ & $E_{6}$ & $\boldsymbol{E}_{7}$ & $\boldsymbol{E}_{8}$ & $\boldsymbol{E}_{9}$ & $E_{10}$ & $W_{i j}$ & $W_{i}$ & $\boldsymbol{W}$ \\
\hline & & $I_{315}$ & 2 & 3 & 6 & 6 & 7 & 6 & 4 & 2 & 3 & 7 & 0.2 & & \\
\hline & \multirow[t]{3}{*}{$I_{32}$} & $I_{321}$ & 4 & 6 & 6 & 7 & 6 & 7 & 2 & 5 & 6 & 7 & 0.35 & \multirow[t]{3}{*}{0.6} & \\
\hline & & $I_{322}$ & 4 & 5 & 2 & 5 & 5 & 8 & 2 & 4 & 2 & 4 & 0.4 & & \\
\hline & & $I_{323}$ & 7 & 7 & 5 & 7 & 9 & 9 & 3 & 7 & 4 & 8 & 0.25 & & \\
\hline \multirow[t]{22}{*}{$I_{4}$} & \multirow[t]{3}{*}{$I_{41}$} & $I_{411}$ & 6 & 3 & 6 & 7 & 8 & 5 & 8 & 5 & 3 & 7 & 0.4 & \multirow[t]{3}{*}{0.25} & \multirow[t]{22}{*}{0.2} \\
\hline & & $I_{412}$ & 7 & 4 & 4 & 7 & 7 & 5 & 8 & 4 & 5 & 8 & 0.35 & & \\
\hline & & $I_{413}$ & 3 & 3 & 4 & 6 & 7 & 4 & 3 & 7 & 4 & 9 & 0.25 & & \\
\hline & \multirow[t]{4}{*}{$I_{42}$} & $I_{421}$ & 1 & 1 & 2 & 3 & 5 & 2 & 0 & 3 & 1 & 3 & 0.2 & \multirow[t]{4}{*}{0.2} & \\
\hline & & $I_{422}$ & 2 & 2 & 4 & 3 & 5 & 3 & 0 & 2 & 1 & 0 & 0.25 & & \\
\hline & & $I_{423}$ & 5 & 5 & 5 & 7 & 7 & 5 & 8 & 4 & 4 & 5 & 0.35 & & \\
\hline & & $I_{424}$ & 5 & 5 & 4 & 6 & 6 & 2 & 3 & 6 & 3 & 5 & 0.2 & & \\
\hline & \multirow[t]{4}{*}{$I_{43}$} & $I_{431}$ & 2 & 4 & 5 & 7 & 5 & 3 & 7 & 5 & 6 & 8 & 0.3 & \multirow[t]{4}{*}{0.15} & \\
\hline & & $I_{432}$ & 2 & 2 & 6 & 6 & 5 & 5 & 3 & 7 & 3 & 5 & 0.2 & & \\
\hline & & $I_{433}$ & 3 & 2 & 2 & 6 & 8 & 3 & 8 & 7 & 5 & 8 & 0.2 & & \\
\hline & & $I_{434}$ & 2 & 7 & 4 & 6 & 5 & 3 & 4 & 3 & 2 & 7 & 0.3 & & \\
\hline & \multirow[t]{4}{*}{$I_{44}$} & $I_{441}$ & 5 & 3 & 2 & 6 & 5 & 3 & 4 & 1 & 3 & 6 & 0.3 & \multirow[t]{4}{*}{0.15} & \\
\hline & & $I_{442}$ & 3 & 3 & 2 & 4 & 3 & 3 & 0 & 3 & 2 & 5 & 0.2 & & \\
\hline & & $I_{443}$ & 5 & 3 & 4 & 5 & 6 & 3 & 3 & 4 & 3 & 5 & 0.3 & & \\
\hline & & $I_{444}$ & 4 & 2 & 4 & 3 & 9 & 3 & 0 & 2 & 4 & 7 & 0.2 & & \\
\hline & \multirow[t]{3}{*}{$I_{45}$} & $I_{451}$ & 7 & 2 & 5 & 5 & 8 & 3 & 8 & 6 & 4 & 5 & 0.3 & \multirow[t]{3}{*}{0.1} & \\
\hline & & $I_{452}$ & 6 & 6 & 5 & 6 & 9 & 7 & 5 & 4 & 6 & 7 & 0.3 & & \\
\hline & & $I_{453}$ & 5 & 6 & 6 & 8 & 7 & 7 & 4 & 7 & 3 & 8 & 0.4 & & \\
\hline & \multirow[t]{4}{*}{$I_{46}$} & $I_{461}$ & 7 & 7 & 3 & 7 & 9 & 7 & 6 & 8 & 7 & 8 & 0.3 & \multirow[t]{4}{*}{0.1} & \\
\hline & & $I_{462}$ & 3 & 2 & 4 & 0 & 5 & 4 & 7 & 1 & 3 & 5 & 0.3 & & \\
\hline & & $I_{463}$ & 4 & 1 & 2 & 2 & 5 & 3 & 5 & 1 & 2 & 5 & 0.25 & & \\
\hline & & $I_{464}$ & 2 & 1 & 2 & 0 & 5 & 1 & 0 & 2 & 1 & 0 & 0.2 & & \\
\hline \multirow[t]{8}{*}{$I_{5}$} & \multirow[t]{2}{*}{$I_{51}$} & $I_{511}$ & 4 & 6 & 5 & 7 & 7 & 4 & 6 & 4 & 5 & 8 & 0.6 & \multirow[t]{2}{*}{0.3} & \multirow[t]{2}{*}{0.3} \\
\hline & & $I_{512}$ & 7 & 4 & 5 & 5 & 6 & 4 & 4 & 6 & 3 & 9 & 0.4 & & \\
\hline & \multirow[t]{3}{*}{$I_{52}$} & $I_{521}$ & 5 & 2 & 5 & 4 & 6 & 2 & 4 & 5 & 2 & 5 & 0.3 & \multirow[t]{3}{*}{0.3} & \\
\hline & & $I_{522}$ & 5 & 6 & 4 & 4 & 7 & 2 & 3 & 3 & 3 & 5 & 0.3 & & \\
\hline & & $I_{523}$ & 3 & 5 & 4 & 4 & 7 & 6 & 3 & 6 & 3 & 5 & 0.4 & & \\
\hline & \multirow[t]{3}{*}{$I_{53}$} & $I_{531}$ & 7 & 5 & 6 & 6 & 8 & 6 & 6 & 4 & 4 & 4 & 0.55 & \multirow[t]{3}{*}{0.45} & \\
\hline & & $I_{532}$ & 6 & 8 & 5 & 6 & 7 & 3 & 7 & 4 & 4 & 9 & 0.25 & & \\
\hline & & $I_{533}$ & 8 & 7 & 5 & 6 & 7 & 3 & 7 & 6 & 3 & 9 & 0.2 & & \\
\hline
\end{tabular}

Legend: $\boldsymbol{I}_{\boldsymbol{i}}=$ Enabler index; $\boldsymbol{I}_{\boldsymbol{i} \boldsymbol{j}}=$ Criterion index; $\boldsymbol{I}_{\boldsymbol{i j k}}=$ Attribute index; $\boldsymbol{E}_{\boldsymbol{i}}=$ Experts participated in the assessment; $\boldsymbol{W}_{\boldsymbol{i j}}=$ Attribute weight; $\boldsymbol{W}_{\boldsymbol{i}}=$ Criterion weight; $\boldsymbol{W}=$ Enabler weight 
Table 3. Indices pertaining to each criterion

\begin{tabular}{|c|c|c|c|c|c|c|c|c|c|c|}
\hline & $E_{1}$ & $E_{2}$ & $E_{3}$ & $E_{4}$ & $E_{5}$ & $E_{6}$ & $E_{7}$ & $E_{8}$ & $E_{9}$ & $E_{10}$ \\
\hline$I_{11}$ & 5 & 4.5 & 4.6 & 6.8 & 5.5 & 5.4 & 5.2 & 5.6 & 3.4 & 4.6 \\
\hline$I_{12}$ & 3.4 & 6.5 & 3.7 & 7 & 7.2 & 5.2 & 3.5 & 3.8 & 3.2 & 5.4 \\
\hline$I_{13}$ & 4.3 & 2.8 & 4.1 & 5.7 & 5.4 & 3.2 & 4 & 1.4 & 3.1 & 2.7 \\
\hline$I_{14}$ & 6.8 & 5 & 5.9 & 7.7 & 5.6 & 5 & 6.3 & 5.1 & 4 & 3.8 \\
\hline$I_{15}$ & 7.65 & 2.85 & 2.5 & 5.65 & 7 & 5.45 & 6.65 & 3.8 & 4.2 & 6.7 \\
\hline$I_{16}$ & 4 & 4.2 & 3 & 5.4 & 6.2 & 4.6 & 4.4 & 4.6 & 4 & 6.8 \\
\hline$I_{21}$ & 2.5 & 3.1 & 2.8 & 5 & 4.4 & 3.7 & 3.8 & 1.7 & 4.4 & 6.6 \\
\hline$I_{22}$ & 2.1 & 3.5 & 4.8 & 5.6 & 5 & 3.9 & 4.9 & 3.6 & 3.7 & 6.4 \\
\hline$I_{23}$ & 3.9 & 4.3 & 4.8 & 5.9 & 5.9 & 4.5 & 5.3 & 3.1 & 4.6 & 6.7 \\
\hline$I_{24}$ & 5 & 4.5 & 5.5 & 6.5 & 7.5 & 4 & 4.5 & 3.5 & 6 & 9 \\
\hline$I_{31}$ & 3 & 4.9 & 5.6 & 5.6 & 6.2 & 5.6 & 5.6 & 3.2 & 3.7 & 4.6 \\
\hline$I_{32}$ & 4.75 & 5.85 & 4.15 & 6.2 & 6.35 & 7.9 & 2.25 & 5.1 & 3.9 & 6.05 \\
\hline$I_{41}$ & 5.6 & 3.35 & 4.8 & 6.75 & 7.4 & 4.75 & 6.75 & 5.15 & 3.95 & 7.85 \\
\hline$I_{42}$ & 3.45 & 3.45 & 3.95 & 5 & 5.9 & 3.3 & 3.4 & 3.7 & 2.45 & 3.35 \\
\hline$I_{43}$ & 2.2 & 4.1 & 4.3 & 6.3 & 5.6 & 3.4 & 5.5 & 5.2 & 4 & 7.1 \\
\hline$I_{44}$ & 4.4 & 2.8 & 3 & 4.7 & 5.7 & 3 & 2.1 & 2.5 & 3 & 5.7 \\
\hline$I_{45}$ & 5.9 & 4.8 & 5.4 & 6.5 & 7.9 & 5.8 & 5.5 & 5.8 & 4.2 & 6.8 \\
\hline$I_{46}$ & 4.4 & 3.15 & 3 & 2.6 & 6.45 & 4.25 & 5.15 & 3.35 & 3.7 & 5.15 \\
\hline$I_{51}$ & 5.2 & 5.2 & 5 & 6.2 & 6.6 & 4 & 5.2 & 4.8 & 4.2 & 8.4 \\
\hline$I_{52}$ & 4.2 & 4.4 & 4.3 & 4 & 6.7 & 3.6 & 3.3 & 4.8 & 2.7 & 5 \\
\hline$I_{53}$ & 6.95 & 6.15 & 5.55 & 6 & 7.55 & 4.65 & 6.45 & 4.4 & 3.8 & 6.25 \\
\hline & & & & & & & \\
\hline
\end{tabular}

Step (3) Calculating each enabler index

The index of each enabler will be calculated also be applying Equation (3). The calculation related to the supplier relationship enabler is given by:

$$
\mathrm{I}_{1}=\mathrm{W}_{1} \times \mathrm{R}_{1}
$$

Weight pertaining to the supplier relationship enabler is given by:

$$
\mathrm{W}_{1}=(0.2,0.2,0.2,0.2,0.1,0.1)
$$

Assessment scores pertaining to the supplier relationship enabler is given by:

$$
\mathrm{R}_{1}=\left[\begin{array}{cccccccccc}
5 & 4.5 & 4.6 & 6.8 & 5.5 & 5.4 & 5.2 & 5.6 & 3.4 & 4.6 \\
3.4 & 6.5 & 3.7 & 7 & 7.2 & 5.2 & 3.5 & 3.8 & 3.2 & 5.4 \\
4.3 & 2.8 & 4.1 & 5.7 & 5.4 & 3.2 & 4 & 1.4 & 3.1 & 2.7 \\
6.8 & 5 & 5.9 & 7.7 & 5.6 & 5 & 6.3 & 5.1 & 4 & 3.8 \\
7.65 & 2.85 & 2.5 & 5.65 & 7 & 5.45 & 6.65 & 3.8 & 4.2 & 6.7 \\
4 & 4.2 & 3 & 5.4 & 6.2 & 4.6 & 4.4 & 4.6 & 4 & 6.8
\end{array}\right]
$$


Index pertaining to the supplier relationship enabler is given by:

$$
\mathrm{I}_{1}=\mathrm{W}_{1} \times \mathrm{R}_{1}
$$

$I_{1}=(5.065,4.465,4.21,6.545,6.06,4.765,4.905,4.02,3.56,4.65)$

Using the same principle, the following indices have been calculated for remaining lean enablers as shown in Table 4.

Table 4. Indices of the enablers

\begin{tabular}{|c|c|c|c|c|c|c|c|c|c|c|}
\hline & $E_{1}$ & $E_{2}$ & $E_{3}$ & $E_{4}$ & $E_{5}$ & $E_{6}$ & $E_{7}$ & $E_{8}$ & $E_{9}$ & $E_{10}$ \\
\hline$I_{1}$ & $\mathbf{5 . 0 6 5}$ & 4.465 & 4.21 & $\mathbf{6 . 5 4 5}$ & $\mathbf{6 . 0 6}$ & $\mathbf{4 . 7 6 5}$ & $\mathbf{4 . 9 0 5}$ & $\mathbf{4 . 0 2}$ & $\mathbf{3 . 5 6}$ & 4.65 \\
\hline$I_{2}$ & $\mathbf{3 . 4 4 5}$ & $\mathbf{3 . 9 9 5}$ & 4.58 & $\mathbf{5 . 9 7}$ & $\mathbf{5 . 8 4}$ & $\mathbf{4 . 2 3 5}$ & $\mathbf{4 . 8 5 5}$ & $\mathbf{3 . 0 4}$ & $\mathbf{4 . 8 2 5}$ & $\mathbf{7 . 3 9}$ \\
\hline$I_{3}$ & 4.05 & 5.47 & 4.73 & 5.96 & $\mathbf{6 . 2 9}$ & $\mathbf{6 . 9 8}$ & $\mathbf{3 . 5 9}$ & $\mathbf{4 . 3 4}$ & $\mathbf{3 . 8 2}$ & $\mathbf{5 . 4 7}$ \\
\hline$I_{4}$ & 4.11 & $\mathbf{3 . 3 5 7 5}$ & $\mathbf{3 . 9 2 5}$ & $\mathbf{5 . 2 4 7 5}$ & $\mathbf{6 . 1 6}$ & $\mathbf{3 . 8 1 2 5}$ & $\mathbf{4 . 5 7 2 5}$ & $\mathbf{4 . 0 9 7 5}$ & $\mathbf{3 . 3 1 7 5}$ & $\mathbf{5 . 7 4 7 5}$ \\
\hline$I_{5}$ & $\mathbf{5 . 9 4 7 5}$ & $\mathbf{5 . 6 4 7 5}$ & $\mathbf{5 . 2 8 7 5}$ & $\mathbf{5 . 7 6}$ & $\mathbf{7 . 3 8 7 5}$ & $\mathbf{4 . 3 7 2 5}$ & $\mathbf{5 . 4 5 2 5}$ & $\mathbf{4 . 8 6}$ & $\mathbf{3 . 7 8}$ & $\mathbf{6 . 8 3 2 5}$ \\
\hline
\end{tabular}

Step (4) Computing the total PSS leanness index

The PSS leanness index for ABC Company has been computed using Equation (1) as:

Overall weight $\mathrm{W}=(0.1,0.2,0.2,0.2,0.3)$

Overall assessment vector $\mathrm{R}=$

$\left[\begin{array}{cccccccccc}5.065 & 4.465 & 4.21 & 6.545 & 6.06 & 4.765 & 4.905 & 4.02 & 3.56 & 4.65 \\ 3.445 & 3.995 & 4.58 & 5.97 & 5.84 & 4.235 & 4.855 & 3.04 & 4.825 & 7.39 \\ 4.05 & 5.47 & 4.73 & 5.96 & 6.29 & 6.98 & 3.59 & 4.34 & 3.82 & 5.47 \\ 4.11 & 3.3575 & 3.925 & 5.2475 & 6.16 & 3.8125 & 4.5725 & 4.0975 & 3.3175 & 5.7475 \\ 5.9475 & 5.6475 & 5.2875 & 5.76 & 7.3875 & 4.3725 & 5.4525 & 4.86 & 3.78 & 6.8325\end{array}\right]$

ABC PSS leanness index

$\mathrm{I}=\mathrm{W} \times \mathrm{R}$

$I=(4.61175,4.70525,4.65425,5.818,6.48025,4.79375,4.72975,4.1555,3.8825,6.23625)$

$I=\frac{1}{10}(4.61175+4.70525+4.65425+5.818,6.48025+4.79375+4.72975+4.1555+3.8825+6.23625)$

$\mathrm{I}=5.006725$ 


\section{Results and discussion}

Based on PSS leanness assessment, the PSS leanness index computed for ABC Company was found to be 5. This indicates that the services offering process provided by ABC Company is generally lean. To enhance the leanness of the company, scope still exists for improving the PSS leanness.

\subsection{Areas for PSS leanness improvement}

Based on the assessment carried out for ABC Company, we can find that there are areas for further improvement. We identified areas for future improvement based on the index and the relative importance (weight) calculated for each enabler and each attribute.

Figure 3(a) shows that the relative importance of customer relationship is $30 \%$ and the index calculated for it is 5.53275. Thus, the first area for improvement will be customer relationship, then process excellence, followed by management leanness and workforce leanness and finally supplier relationship.

\subsubsection{Customer relationship}

The index calculated for customer relationship is based on the indices computed for the customer relationship attributes as presented in Figure 3(f). It is obvious that more improvements are required in customer response adoption. The index calculated for customer response adoption is 4.3 with a weight of $30 \%$. This attribute can be improved by:

- Usage of a well-defined Voice of Customer (VOC)

- Identifying customers touch points

- Empowerment of employees to solve customers' problems

\subsection{2. $\quad$ Process excellence}

The second enabler that needs more improvement is process excellence. The process excellence index is 4.43475 and it is the outcome of the indices calculated for the criteria pertaining to process excellence as shown in Figure 3(e).

The first area that needs more improvement regarding process excellence is the streamline of process and this can be achieved by:

- Using value stream mapping

- Quantifying the seven types of wastes

- $\quad$ Trying to pull the work 


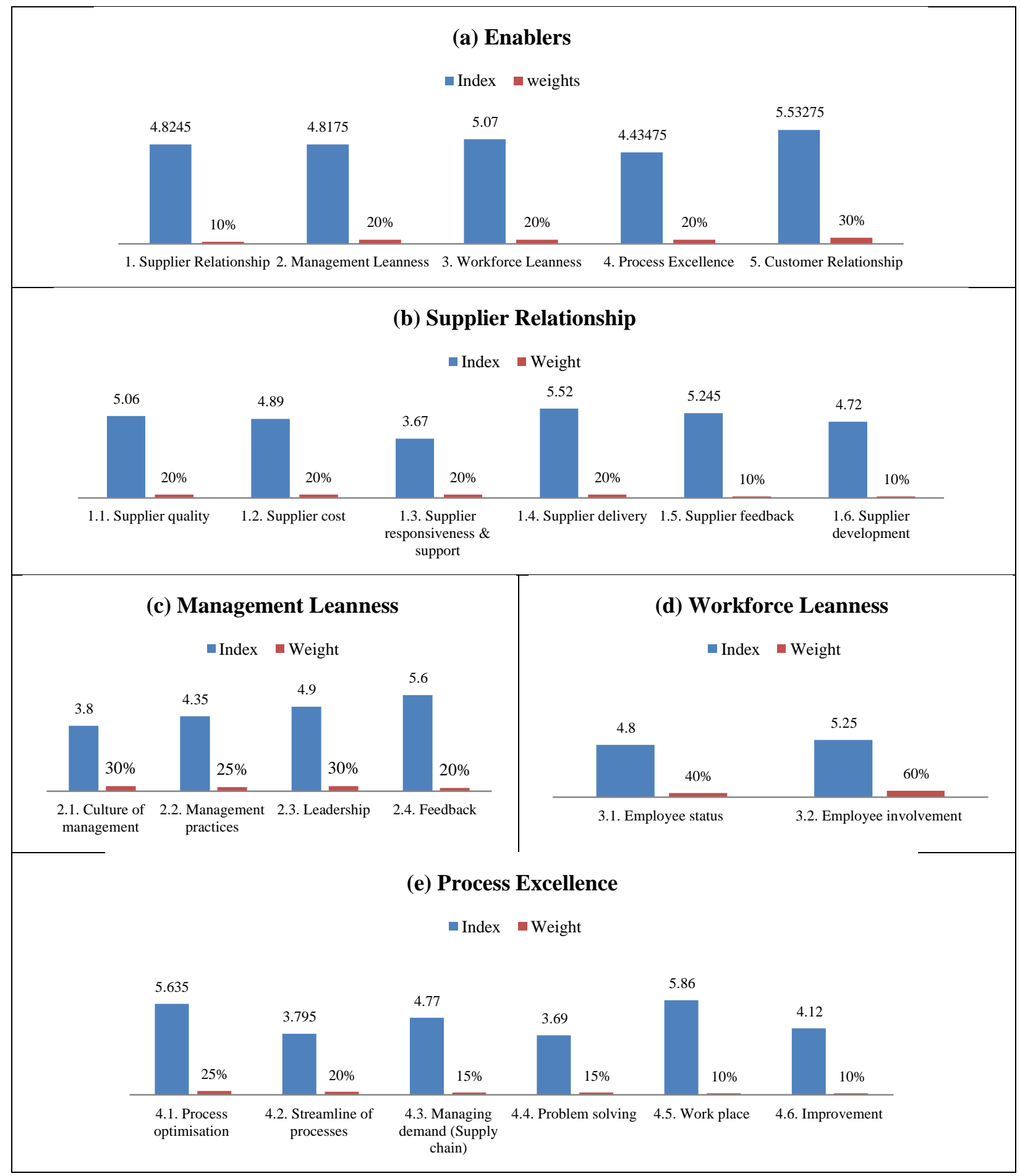

Figure 3. Areas for further improvement 


\section{(f) Customer Relationship}

Index $\quad$ Weight

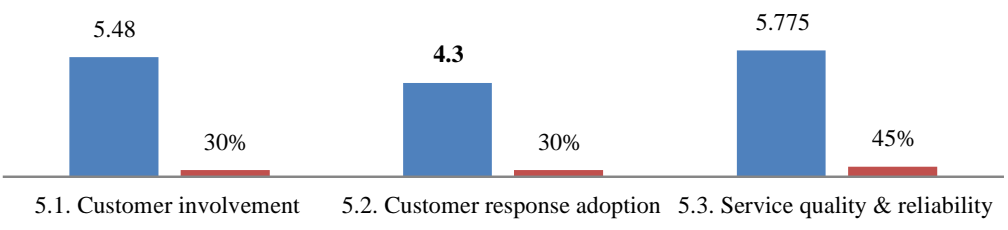

Figure 3. Areas for further improvement

The second area that needs more improvement is problem solving. This can be achieved by:

- Exposing employees to problem solving techniques and tools

- Use problem solving techniques like root cause analysis

- Defining an action plan for each problem

- Using statistical techniques to reduce process variance

The third criteria pertaining to process excellence that should be improved is continuous improvement. This can be done by:

- Using Kaizen and 5s

- Existence of improvement teams

- Existence of future state maps

\subsubsection{Management leanness}

The third enabler that needs enhancement is management leanness. Figure 3(c) shows the criteria pertaining to management leanness.

From Figure 3 (c), it is clear that the first area that should be improved is the culture of management. The index of management culture was 3.8 because:

- There is no clear understanding among managers that lean is not just about tools and techniques

- Lean thinking is not an integral part in offering services to customers

- Lack of problem prevention and waste elimination culture

\subsubsection{Workforce leanness}

The fourth enabler that needs further development is workforce leanness. Workforce leanness consists of two criteria as shown in Figure 3 (d).

Workforce leanness can be developed by enhancing employee status, this can be done by: 
- Implementing job rotation system

- Communicating a culture of continuous improvement among employees

- Identifying internal and external customer for each employee

\subsubsection{Supplier relationship}

The final enabler that requires some improvement is supplier relationship. There are six criteria pertaining to supplier relationship as shown in Figure 3 (a). Further improvement is required to enhance supplier responsiveness and support, where suppliers have to:

- Be sensitive to complains

- Have a culture of waste elimination

- Provide more after sales services and support

\section{Validation}

In order to practically explore the feasibility and applicability of the leanness model, two types of validations were conducted, namely qualitative and quantitative.

\subsection{Qualitative validation}

In a group discussion with the ten experts engaged in the evaluation process, the PSS leanness index, as well as areas for further improvements were presented. The experts have been asked if:

- The index represents their views as to what degree PSS leanness had been adopted

- The areas of improvements show the company's present situation.

- There were any missing items or items that should be excluded from the model

The experts argued that the index reflects the current position and the situation of the company's activities, moreover there was a consensus between the experts on the proposed improvement areas. Additionally, they declared that the model is inclusive covering all the elements and they did not propose any alterations on the model.

\subsection{Quantitative validation}

At the end of the group discussion, the ten experts were asked to independently fill a validation questionnaire. There were four questions in the validation questionnaire and every expert should choose from a Likert's scale ranging from 0 to 10. After analysing the answers, it was found that the PSS leanness assessment model is appropriate and can be successfully implemented. All the answers of the experts are presented in Appendix 2. 


\section{Conclusions}

Literature reported numerous methods and instruments to measure the effectiveness of lean implementation either in the manufacturing industry or in the service industry. There is a lack of research efforts that investigate the implementation of lean thinking in PSS. Thus, the purpose of this research is to develop a model that can measure the degree of PSS leanness in a manufacturing company. The research commenced with the development of the conceptual model. The model was developed in an iterative process between theoretical and empirical insights. Starting from existing literature on lean assessment in manufacturing and service sectors and ending with semi-structured interviews with experts from the industry. The final version of the model involves three levels that will be used in the assessment process. The first level consists of five enablers, the second level consists of twenty-one criteria and finally the third level includes 73 attributes. After the development of the conceptual model, the PSS leanness index has been calculated and areas for further improvements have been identified. Lastly, the results derived from the model were validated using qualitative and quantitative approach. The validation demonstrated that the model and the results generated from using it are feasible.

\subsection{Managerial and theoretical implications}

Since lean assessment gains importance, many models and techniques have been developed to evaluate the performance of lean and the term leanness have been used as a metric to assess the current level of lean implementation.

Despite the vast research published on leanness either on manufacturing or non-manufacturing sectors, the extant literature fails to provide a method or instrument that can be used to measure the degree of PSS leanness. Accordingly, this paper presents a comprehensive assessment model that can be employed to identify the leanness level of PSS via an index that measures the lean status of the process of providing services to customers.

The calculated PSS leanness index can help manufacturing companies' managers to reveal how lean the service offering process is; indicates how lean the service offering process should be; and demonstrates how to achieve the desired leanness level. Additionally, this assessment model supports manufacturing companies in their continuous improvement initiatives.

\subsection{Study limitations and future research}

This study focused on a single case company that may affect the generalisability of the model. Additionally, it is based on the experts' opinions, this may tend to be biased. In the future, the assessment model needs to be validated and implemented by more manufacturing companies from different industries to enhance the generalisability of the model. 
One more limitation that occurred at the validation of the assessment model is some of the experts who participated in the validation of the assessment model, also participated in its development and refinement. This could cause bias since their views were already considered at the development stage. However, the other experts who were not involved at the development stage reduced the issues of bias.

Moreover, the PSS leanness assessment model did not include any direct financial performance factors. Financial parameters are an important factor that needs to be considered in the assessment process. Future research can include any financial performance indicators in the assessment process.

In the calculations of the PSS leanness index, multi-grade method has been used to compute the index. Other calculation methods have not been considered in this research. In the future, it will be necessary to compare the proposed method with other calculation methods such as Analytical Network Process (ANP), Analytical Hierarchy Process (AHP), structural equation model, and artificial neural network.

\section{References}

Al-Najem, M., Dhakal, H., Labib, A. and Bennett, N. (2013), "Lean readiness level within Kuwaiti manufacturing industries", International Journal of Lean Six Sigma, Vol. 4 No. 3, pp. 280-320.

Alemi, M.A. and Akram, R. (2013), "Measuring the leanness of manufacturing systems by using fuzzy TOPSIS: A case study of the'Parizan Sanat'company", South African Journal of Industrial Engineering, Vol. 24 No. 3, pp. 166-174.

Almutairi, A.M., Salonitis, K. and Al-Ashaab, A. (2019), "Assessing the leanness of a supply chain using multi-grade fuzzy logic: a health-care case study”, International Journal of Lean Six Sigma, Vol. 10 No. 1, pp. 81-105.

Amin, M.A., Alam, M.R., Alidrisi, H. and Karim, M.A. (2020), “A fuzzy-based leanness evaluation model for manufacturing organisations”, Production Planning and Control, Taylor \& Francis, Vol. 0 No. 0, pp. 1-16.

Antony, J. and Desai, D.A. (2009), "Assessing the status of six sigma implementation in the Indian industry: Results from an exploratory empirical study", Management Research News, Vol. 32 No. 5, pp. 413423.

Anvari, A., Zulkifli, N. and Yusuff, R.M. (2013), "A dynamic modeling to measure lean performance within lean attributes”, International Journal of Advanced Manufacturing Technology, Vol. 66 No. 5-8, pp. 663-677.

Apte, U.M. and Goh, C.-H. (2004), “Applying lean manufacturing principles to information intensive services”, International Journal of Services Technology and Management, Vol. 5 No. 5-6, pp. 488506.

Arya, A.K. and Choudhary, S. (2015), "Assessing the application of Kaizen principles in Indian small-scale industry”, International Journal of Lean Six Sigma, Vol. 6 No. 4, pp. 369-396.

Azadeh, A., Zarrin, M., Abdollahi, M., Noury, S. and Farahmand, S. (2015), "Leanness assessment and optimization by fuzzy cognitive map and multivariate analysis", Expert Systems with Applications, Elsevier Ltd, Vol. 42 No. 15-16, pp. 6050-6064. 
Baines, T.S., Lightfoot, H.W., Evans, S., Neely, A., Greenough, R., Peppard, J., Roy, R., et al. (2007), "State-of-the-art in product-service systems", Proceedings of the Institution of Mechanical Engineers, Part B: Journal of Engineering Manufacture, Vol. 221 No. 10, pp. 1543-1552.

Bayou, M.E. and Korvin, A. De. (2008), "Measuring the leanness of manufacturing systems-a case study of Ford Motor Company and General Motors", Journal of Engineering and Technology Management, Vol. 25 No. 4, pp. 287-304.

Bhasin, S. (2011), "Measuring the Leanness of an organisation", International Journal of Lean Six Sigma, Vol. 2 No. 1, pp. 55-74.

Bhasin, S. (2012), "An appropriate change strategy for lean success", Management Decision, Vol. 50 No. 3 , pp. 439-458.

Bhasin, S. and Burcher, P. (2006), "Lean viewed as a philosophy", Journal of Manufacturing Technology Management, Vol. 17 No. 1, pp. 56-72.

Bicheno, J. (2008), The Lean Toolbox for Service Systems, PICSIE books.

Bidhendi, S., Goh, S. and Wandel, A. (2019), "Development of a weighted leanness measurement method in modular construction companies", Journal of Industrial Engineering International, Springer Berlin Heidelberg, Vol. 15 No. 4, pp. 603-625.

Burch, V. and Smith, B. (2019), "Using simulation to teach lean methodologies and the benefits for Millennials", Total Quality Management \& Business Excellence, Vol. 30 No. 3-4, pp. 320-334.

Cook, M.B., Bhamra, T.A. and Lemon, M. (2006), "The transfer and application of Product Service Systems: from academia to UK manufacturing firms", Journal of Cleaner Production, Vol. 14 No. 17, pp. $1455-1465$.

Cuatrecasas, L. (2004), “A lean management implementation method in service operations”, International Journal of Services Technology and Management, Vol. 5 No. 5-6, pp. 532-544.

Dahda, S.S., Andesta, D. and Wicaksono, A.S. (2020), "Measuring leanness index using fuzzy logic approach", Journal of Physics: Conference Series, Vol. 1469 No. 1, available at:https://doi.org/10.1088/1742-6596/1469/1/012040.

Delgado, C., Ferreira, M. and Branco, M.C. (2010), "The implementation of lean Six Sigma in financial services organizations", Journal of Manufacturing Technology Management, Vol. 21 No. 4, pp. 512523.

Elnadi, M. and Shehab, E. (2015), "Main enablers and factors for successful implementation of lean in product-service systems", International Journal of Agile Systems and Management, Vol. 8 No. 3-4, available at:https://doi.org/10.1504/IJASM.2015.073542.

Elnadi, M. and Shehab, E. (2016), “A multiple-case assessment of productservice system leanness in UK manufacturing companies", Proceedings of the Institution of Mechanical Engineers, Part B: Journal of Engineering Manufacture, Vol. 230 No. 3, pp. 574-586.

Garza-Reyes, J.A., Betsis, I.E., Kumar, V. and Al-Shboul, M.A.R. (2018), "Lean readiness-the case of the European pharmaceutical manufacturing industry", International Journal of Productivity and Performance Management, Vol. 67 No. 1, pp. 20-44.

Goodson, R.E. (2002), "Read a plant-fast”, Harvard Business Review, Vol. 80 No. 5, pp. 105-113.

Guimarães, C.M. and de Carvalho, J.C. (2014), "Assessing lean deployment in healthcare-A critical review and framework", Journal of Enterprise Transformation, Vol. 4 No. 1, pp. 3-27.

Gupta, V., Acharya, P. and Patwardhan, M. (2013), "A strategic and operational approach to assess the lean 
performance in radial tyre manufacturing in India: a case based study", International Journal of Productivity and Performance Management, Vol. 62 No. 6, pp. 634-651.

Handfield, R.B. (1993), “A resource dependence perspective of just-in-time purchasing”, Journal of Operations Management, Vol. 11 No. 3, pp. 289-311.

Harris, C. and Harris, R. (2007), Developing a Lean Workforce: A Guide for Human Resources, Plant Managers, and Lean Coordinators, Productivity Press.

Kalyan, C., Abhirama, T., Mohammed, N.R., Raj, S.A. and Jayakrishna, K. (2019). Using Multi-Grade Fuzzy Approach, Springer Singapore, available at:https://doi.org/10.1007/978-981-13-6374-0.

Karlsson, C. and Åhlström, P. (1996), “Assessing changes towards lean production”, International Journal of Operations \& Production Management, Vol. 16 No. 2, pp. 24-41.

Karvonen, T., Rodriguez, P., Kuvaja, P., Mikkonen, K. and Oivo, M. (2012), “Adapting the lean enterprise self-assessment tool for the software development domain", Proceedings - 38th EUROMICRO Conference on Software Engineering and Advanced Applications, SEAA 2012, pp. 266-273.

Kumar, S., Singh, B., Qadri, M.A., Kumar, Y.V.S. and Haleem, A. (2013), “A framework for comparative evaluation of lean performance of firms using fuzzy TOPSIS", International Journal of Productivity and Quality Management, Vol. 11 No. 4, pp. 371-392.

Kumar Singh, R. and Modgil, S. (2020), Assessment of Lean Supply Chain Practices in Indian Automotive Industry, Global Business Review, available at:https://doi.org/10.1177/0972150919890234.

Lee, R.G. and Dale, B.G. (1998), "Business process management: a review and evaluation", Business Process Management Journal, Vol. 4 No. 3, pp. 214-225.

Liu, C., Niu, Z., Chang, P.-C. and Zhang, B. (2017), “Assessment approach to stage of lean transformation cycle based on fuzzy nearness degree and TOPSIS", International Journal of Production Research, Vol. 55 No. 23, pp. 7223-7235.

Loyd, N., Harris, G., Gholston, S. and Berkowitz, D. (2020), "Development of a lean assessment tool and measuring the effect of culture from employee perception", Journal of Manufacturing Technology Management, Vol. ahead-of-p No. ahead-of-print, available at:https://doi.org/10.1108/jmtm-10-20190375 .

MacDuffie, J.P. and Helper, S. (1997), "Creating lean suppliers: diffusing lean production through the supply chain”, California Management Review, Vol. 39 No. 4, pp. 118-151.

Makui, A., Ghousi, R., Jahani, E., Hamidi, M.R. and Babaei, M.H. (2014), "Total Rapid Assessment (TRA) A comprehensive Method for Rapid Plant Assessment", Applied Mathematics in Engineering, Management and Technology, Vol. 2 No. 1, pp. 301-316.

Malmbrandt, M. and Åhlström, P. (2013), “An instrument for assessing lean service adoption”, International Journal of Operations \& Production Management, Vol. 33 No. 9, pp. 1131-1165.

Mann, D. (2017), Creating a Lean Culture: Tools to Sustain Lean Conversions, Productivity Press.

Martinez, F. (2019), "Lean home services in Czech Republic", International Journal of Lean Six Sigma, Vol. 10 No. 3, pp. 784-802.

Matawale, C.R., Datta, S. and Mahapatra, S.S. (2015), "Leanness metric evaluation platform in fuzzy context", Journal of Modelling in Management, Vol. 10 No. 2, pp. 238-267.

Maussang, N., Zwolinski, P. and Brissaud, D. (2009), "Product-service system design methodology: from the PSS architecture design to the products specifications", Journal of Engineering Design, Vol. 20 No. 4, pp. 349-366. 
Mishra, R. and Mishra, O.N. (2018), "A hybrid PCA-AHP-Multi-grade Fuzzy approach to assess marketing-based flexibility”, Marketing Intelligence and Planning, Vol. 36 No. 2, pp. 213-229.

Mont, O.K. (2002), "Clarifying the concept of product-service system", Journal of Cleaner Production, Vol. 10 No. 3, pp. 237-245.

Nallusamy, S., Ganesan, M., Balakannan, K. and Shankar, C. (2016), "Environmental sustainability evaluation for an automobile manufacturing industry using multi-grade fuzzy approach", International Journal of Engineering Research in Africa, Vol. 19, pp. 123-129.

Narayanamurthy, G. and Gurumurthy, A. (2016a), "Systemic leanness: An index for facilitating continuous improvement of lean implementation", Journal of Manufacturing Technology Management, Vol. 27 No. 8, pp. 1014-1053.

Narayanamurthy, G. and Gurumurthy, A. (2016b), "Leanness assessment: a literature review", International Journal of Operations and Production Management, Vol. 36 No. 10, pp. 1115-1160.

Narayanamurthy, G., Gurumurthy, A., Subramanian, N. and Moser, R. (2018), "Assessing the readiness to implement lean in healthcare institutions-A case study", International Journal of Production Economics, Vol. 197, pp. 123-142.

Nightingale, D.J. and Mize, J.H. (2002), "Development of a lean enterprise transformation maturity model", Information Knowledge Systems Management, Vol. 3 No. 1, pp. 15-30.

Pagliosa, M., Tortorella, G. and Ferreira, J.C.E. (2019), "Industry 4.0 and Lean Manufacturing: A systematic literature review and future research directions", Journal of Manufacturing Technology Management, available at:https://doi.org/10.1108/JMTM-12-2018-0446.

Pakdil, F. and Leonard, K.M. (2014), "Criteria for a lean organisation: Development of a lean assessment tool”, International Journal of Production Research, Taylor \& Francis, Vol. 52 No. 15, pp. 45874607.

Piercy, N. and Rich, N. (2009), "Lean transformation in the pure service environment: the case of the call service centre", International Journal of Operations \& Production Management, Vol. 29 No. 1, pp. $54-76$.

Radnor, Z. and Bucci, G. (2011), "Analysis of lean implementation in UK business schools and universities", Association of Business Schools, London, p. 74.

Sakao, T., Sandström, G.Ö. and Matzen, D. (2009), "Framing research for service orientation of manufacturers through PSS approaches", Journal of Manufacturing Technology Management, Vol. 20 No. 5, pp. 754-778.

Saleeshya, P.G. and Binu, M. (2019), “A neuro-fuzzy hybrid model for assessing leanness of manufacturing systems”, International Journal of Lean Six Sigma, Vol. 10 No. 1, pp. 473-499.

Sangwa, N.R. and Sangwan, K.S. (2018), "Leanness assessment of organizational performance: a systematic literature review", Journal of Manufacturing Technology Management, Vol. 29 No. 5, pp. 768-788.

dos Santos Bento, G. and Tontini, G. (2019), "Maturity of lean practices in Brazilian manufacturing companies", Total Quality Management \& Business Excellence, Vol. 30 No. sup1, pp. S114-S128.

Saxby, R., Cano-Kourouklis, M. and Viza, E. (2020), “An initial assessment of Lean Management methods for Industry 4.0”, TQM Journal, Vol. 32 No. 4, pp. 587-601.

Seyedhosseini, S.M. and Ebrahimi-Taleghani, A. (2015), "Group fuzzy ANP procedure development for leanness assessment in auto part manufacturing companies", Journal for Global Business 
Advancement, Vol. 8 No. 2, pp. 157-175.

Sisson, J.A. (2019), "Maturing the lean capability of front-line operations supervisors", International Journal of Lean Six Sigma, Vol. 10 No. 1, pp. 2-22.

Soriano-Meier, H. and Forrester, P.L. (2002), "A model for evaluating the degree of leanness of manufacturing firms", Integrated Manufacturing Systems, Vol. 13 No. 2, pp. 104-109.

Sreedharan, R., Raju, R., Sunder M, V. and Antony, J. (2019), "Assessment of Lean Six Sigma Readiness (LESIRE) for manufacturing industries using fuzzy logic", International Journal of Quality and Reliability Management, Vol. 36 No. 2, pp. 137-161.

Sridharan, V. and Suresh, M. (2017), "Environmental sustainability assessment using multigrade fuzzy-A case of two Indian colleges", 2016 IEEE International Conference on Computational Intelligence and Computing Research, ICCIC 2016, pp. 6-9.

Stone, K.B. (2012), "Lean transformation: Organizational performance factors that influence firms' leanness", Journal of Enterprise Transformation, Vol. 2 No. 4, pp. 229-249.

Suárez-Barraza, M.F. and Ramis-Pujol, J. (2010), "Implementation of Lean-Kaizen in the human resource service process", Journal of Manufacturing Technology Management, Vol. 21 No. 3, pp. 388-410.

Suresh, M. and Patri, R. (2017), "Agility assessment using fuzzy logic approach: A case of healthcare dispensary”, BMC Health Services Research, BMC Health Services Research, Vol. 17 No. 1, pp. 113.

Susilawati, A., Tan, J., Bell, D. and Sarwar, M. (2015), "Fuzzy logic based method to measure degree of lean activity in manufacturing industry", Journal of Manufacturing Systems, Vol. 34, pp. 1-11.

Swank, C.K. (2003), "The lean service machine", Harvard Business Review, Vol. 81 No. 10, pp. 123-130.

Tortorella, G.L., Rosa, M.V.L.L., Caiado, R., Nascimento, D. and Sawhney, R. (2019), “Assessment of Lean implementation in Hotels' supply chains", Production, Vol. 29.

Trkman, P. (2010), "The critical success factors of business process management”, International Journal of Information Management, Vol. 30 No. 2, pp. 125-134.

Tukker, A. (2004), "Eight types of product-service system: eight ways to sustainability? Experiences from SusProNet", Business Strategy and the Environment, Vol. 13 No. 4, pp. 246-260.

Tukker, A. and Tischner, U. (2006), "Product-services as a research field: past, present and future. Reflections from a decade of research", Journal of Cleaner Production, Vol. 14 No. 17, pp. 15521556.

Urban, W. (2015), “The lean management maturity self-assessment tool based on organizational culture diagnosis", Procedia-Social and Behavioral Sciences, Vol. 213, pp. 728-733.

Vidyadhar, R., Kumar, R.S., Vinodh, S. and Antony, J. (2016), "Application of fuzzy logic for leanness assessment in SMEs: a case study", Journal of Engineering, Design and Technology, Vol. 14 No. 1, pp. 78-103.

Vimal, K.E.K. and Vinodh, S. (2013), "Application of artificial neural network for fuzzy logic based leanness assessment", Journal of Manufacturing Technology Management, Vol. 24 No. 2, pp. 274292.

Vimal, K.E.K., Vinodh, S. and Muralidharan, R. (2015), "An approach for evaluation of process sustainability using multi-grade fuzzy method", International Journal of Sustainable Engineering, Taylor \& Francis.

Vinodh, S. and Balaji, S.R. (2011), "Fuzzy logic based leanness assessment and its decision support 
system", International Journal of Production Research, Vol. 49 No. 13, pp. 4027-4041.

Vinodh, S. and Chintha, S.K. (2011), "Leanness assessment using multi-grade fuzzy approach", International Journal of Production Research, Vol. 49 No. 2, pp. 431-445.

Vinodh, S., Devadasan, S.R., Vasudeva Reddy, B. and Ravichand, K. (2010), "Agility index measurement using multi-grade fuzzy approach integrated in a 20 criteria agile model”, International Journal of Production Research, Vol. 48 No. 23, pp. 7159-7176.

Womack, J.P. and Jones, D.T. (1996), "Beyond Toyota: how to root out waste and pursue perfection", Harvard Business Review, Vol. 74 No. 5, pp. 140-158.

Wong, W.P., Ignatius, J. and Soh, K.L. (2014), "What is the leanness level of your organisation in lean transformation implementation? An integrated lean index using ANP approach", Production Planning \& Control, Vol. 25 No. 4, pp. 273-287.

Yadav, V., Khandelwal, G., Jain, R. and Mittal, M.L. (2019), "Development of leanness index for SMEs", International Journal of Lean Six Sigma, Vol. 10 No. 1, pp. 397-410.

Yang, X., Moore, P., Pu, J.-S. and Wong, C.-B. (2009), “A practical methodology for realizing product service systems for consumer products”, Computers \& Industrial Engineering, Vol. 56 No. 1, pp. 224-235.

Yin, R.K. (2017), Case Study Research and Applications: Design and Methods, Sage publications. 
Appendix 1

\begin{tabular}{|c|c|c|}
\hline Enabler $\left(I_{i}\right)$ & Criteria $\left(I_{i j}\right)$ & Attributes $\left(I_{i j k}\right)$ \\
\hline \multirow[t]{6}{*}{ 1. Supplier Relationship } & 1.1. Supplier quality & $\begin{array}{l}\text { 1.1.1 Use process controls \& stress defect prevention } \\
\text { 1.1.2. Strive for continual improvement in quality in all facets of operations } \\
\text { 1.1.3. Have a documented quality system } \\
\text { 1.1.4. Deliveries arrive in the right quality }\end{array}$ \\
\hline & 1.2. Supplier cost & $\begin{array}{l}\text { 1.2.1. Price Competitiveness } \\
1.2 .2 \text {. Cost control efficiency } \\
\text { 1.2.3. Flexibility in payment }\end{array}$ \\
\hline & 1.3. Supplier responsiveness \& support & $\begin{array}{l}\text { 1.3.1. Sensitivity to complains } \\
\text { 1.3.2. Information transparency } \\
\text { 1.3.3. Culture of waste elimination compatibility } \\
\text { 1.3.4. Service \& support after sales }\end{array}$ \\
\hline & 1.4. Supplier delivery & $\begin{array}{l}\text { 1.4.1. Deliveries arrive on time and in the right amount every time } \\
\text { 1.4.2. Delivery lead time } \\
\text { 1.4.3. Time flexibility } \\
\text { 1.4.4. Key suppliers are located close }\end{array}$ \\
\hline & 1.5. Supplier feedback & $\begin{array}{l}\text { 1.5.1. Close contact with suppliers } \\
\text { 1.5.2. Regular feedback is given to suppliers on their performance } \\
\text { 1.5.3. Striving to establish long-term relationship with suppliers }\end{array}$ \\
\hline & 1.6. Supplier development & $\begin{array}{l}\text { 1.6.1. Regular training is conducted for suppliers' employees } \\
\text { 1.6.2. Supplier selection is not based only on cost, but on a set of value-adds } \\
\text { 1.6.3. Usage intension of new technology } \\
\text { 1.6.4. Attention to new product development }\end{array}$ \\
\hline \multirow[t]{4}{*}{ 2. Management Leanness } & 2.1. Culture of management & $\begin{array}{l}\text { 2.1.1. The clear understanding that lean is not just about tools, but a philosophy } \\
\text { 2.1.2. Lean thinking is an integral part in offering services to customers } \\
\text { 2.1.3. Culture of problem prevention \& waste elimination }\end{array}$ \\
\hline & 2.2. Management practices & $\begin{array}{l}\text { 2.2.1. Daily accountability process } \\
\text { 2.2.2. Team management for decision making } \\
\text { 2.2.3. Process focused management } \\
\text { 2.2.4. Smooth information flow }\end{array}$ \\
\hline & 2.3. Leadership & $\begin{array}{l}\text { 2.3.1. Lean services is driven by the CEO } \\
\text { 2.3.2. Leaders refer to employees as associates } \\
\text { 2.3.3. Leaders spend a lot of time coaching, mentoring, leading by example } \\
\text { 2.3.4. Leaders consistently seek to understand changing customer needs }\end{array}$ \\
\hline & 2.4. Feedback & $\begin{array}{l}\text { 2.4.1. Ongoing measurement of performance } \\
\text { 2.4.2. Usage of dashboard for sharing performance }\end{array}$ \\
\hline
\end{tabular}


Appendix 1 (Continued)

\begin{tabular}{|c|c|c|}
\hline Enabler $\left(I_{i}\right)$ & Criteria $\left(I_{i j}\right)$ & Attributes $\left(I_{i j k}\right)$ \\
\hline \multirow[t]{2}{*}{ 3. Workforce Leanness } & 3.1. Employee status & $\begin{array}{l}\text { 3.1.1. Flexible workforce } \\
\text { 3.1.2. Multi-skilled personnel } \\
\text { 3.1.3. Implementation of job rotation system } \\
\text { 3.1.4. Each employee knows his internal and external customer } \\
\text { 3.1.5. Culture of continuous improvement }\end{array}$ \\
\hline & 3.2. Employee involvement & $\begin{array}{l}\text { 3.2.1. Strong employee spirit and cooperation } \\
\text { 3.2.2. Employee empowerment } \\
\text { 3.2.3. Regular meetings are held with employees }\end{array}$ \\
\hline \multirow[t]{6}{*}{ 4. Process Excellence } & 4.1. Process optimisation & $\begin{array}{l}\text { 4.1.1. Processes have defined purpose and objective } \\
\text { 4.1.2. Processes have defined standards } \\
\text { 4.1.3. Potential risks have identified for all processes }\end{array}$ \\
\hline & 4.2. Streamline of processes & $\begin{array}{l}\text { 4.2.1. Adoption of value stream mapping } \\
\text { 4.2.2. Quantification of seven wastes } \\
\text { 4.2.3. On time delivery to customers } \\
\text { 4.2.4. Work is pulled }\end{array}$ \\
\hline & 4.3. Managing demand (Supply chain) & $\begin{array}{l}\text { 4.3.1. Customers are contacted proactively } \\
\text { 4.3.2. Extra capacity to handle unpredictable demand } \\
\text { 4.3.3. Supply at the pull of the customer } \\
\text { 4.3.4. Optimising the cost of inventory }\end{array}$ \\
\hline & 4.4. Problem solving & $\begin{array}{l}\text { 4.4.1. Employees are exposed to problem solving tools and techniques } \\
\text { 4.4.2. Root cause analysis (Fishbone diagram) } \\
\text { 4.4.3. Each problem has a well-defined action plan } \\
\text { 4.4.4. Use of statistical techniques to reduce process variance }\end{array}$ \\
\hline & 4.5. Workplace & $\begin{array}{l}\text { 4.5.1. Usage of automated tools to enhance the services } \\
\text { 4.5.2. Active policy to help keep work areas clean and tidy } \\
\text { 4.5.3. Service centres well equipped with spares }\end{array}$ \\
\hline & 4.6. Improvement & $\begin{array}{l}\text { 4.6.1. Regular audits are carried out } \\
\text { 4.6.2. Usage of Kaizen \& } 5 \mathrm{~s} \\
\text { 4.6.3. Existence of improvement team } \\
\text { 4.6.4. Existence of future state maps }\end{array}$ \\
\hline \multirow[t]{3}{*}{ 5. Customer Relationship } & 5.1. Customer involvement & $\begin{array}{l}\text { 5.1.1. Close contact with customers } \\
\text { 5.1.2. Customers give feedback on quality, cost and delivery performance }\end{array}$ \\
\hline & 5.2. Customer response adoption & $\begin{array}{l}\text { 5.2.1. Usage of a well-defined VOC } \\
\text { 5.2.2. Customer touch points have been identified } \\
\text { 5.2.3. Empowerment of employees to resolve customer problems }\end{array}$ \\
\hline & 5.3. Service quality \& reliability & $\begin{array}{l}\text { 5.3.1. Service consistently meets customers' expectations } \\
\text { 5.3.2. Service is available when desired } \\
\text { 5.3.3. Scheduling of customer service }\end{array}$ \\
\hline
\end{tabular}


Appendix. 2

\begin{tabular}{|c|c|c|c|c|c|c|c|c|c|c|c|}
\hline Question & $\mathbf{E}_{1}$ & $\mathbf{E}_{2}$ & $\mathbf{E}_{3}$ & $\mathbf{E}_{4}$ & $\mathbf{E}_{5}$ & $\mathbf{E}_{6}$ & $\mathbf{E}_{7}$ & $\mathbf{E}_{8}$ & E9 & $\mathbf{E}_{10}$ & Average \\
\hline $\begin{array}{l}\text { 1. To what extent do you believe that the model used } \\
\text { in the evaluation is practically feasible in your } \\
\text { company? }\end{array}$ & 8 & 7 & 8 & 8 & 9 & 9 & 9 & 7 & 8 & 9 & 8.2 \\
\hline $\begin{array}{l}\text { 2. To what extent do you believe that the model used } \\
\text { in the evaluation is understandable? }\end{array}$ & 8 & 8 & 7 & 9 & 9 & 8 & 9 & 8 & 7 & 9 & 8.2 \\
\hline $\begin{array}{l}\text { 3. To what extent do you believe that the PSS } \\
\text { leanness index represents the reality of your } \\
\text { company? }\end{array}$ & 8 & 8 & 8 & 9 & 8 & 9 & 9 & 9 & 8 & 9 & 8.5 \\
\hline $\begin{array}{l}\text { 4. To what extent do you believe that the model is } \\
\text { comprehensive and cover lean perspectives? }\end{array}$ & 8 & 8 & 7 & 10 & 9 & 9 & 8 & 8 & 9 & 10 & 8.6 \\
\hline
\end{tabular}


$2021-02-12$

\section{Product-service system leanness}

\section{assessment model: study of a UK manufacturing company}

\section{Elnadi, Moustafa}

Emerald

Elnadi M, Shehab E. (2021) Product-service system leanness assessment model: study of a UK manufacturing company. International Journal of Lean Six Sigma, Volume 12, Number 5, October 2021, pp. 1046-1072

https://doi.org/10.1108/lJLSS-03-2020-0036

Downloaded from Cranfield Library Services E-Repository 